\title{
Counterfactual Theory as an Under-Utilised Analytical Framework for Studying Precarious
}

\section{Work Experiences}

\begin{abstract}
Purpose - The present article seeks to explore experiences and attitudes associated with 'precarious work', an umbrella term for insecure, casual, flexible, contingency, non-standard and zero-hour types of employment.

Design/methodology/approach - The investigation was carried-out through two studies. The "outside-in" view was represented by business undergraduates $(n=56)$, responding to a four-item questionnaire on precarious work. It was contrasted with the "inside-out" perspective of migrant, care and hospitality workers $(n=72)$ expressed in 48 in-depth interviews, and four focus groups.
\end{abstract}

Findings - Participant narratives included counterfactual comparisons that were more often of a downward ("it could have been worse") than of an upward ("not as good as it could have been") kind. Precarious participants spontaneously remarked that they were "lucky" (rather than "unlucky") to be in precarious work.

Implications - Precarious work is likely to give rise to insecurity, uncertainty and vulnerability. However, this study distinguishes between the perspectives of "outside-in" observers, and "insideout" participants. The former view was aligned with the standard view of work social scientists, yet the latter ran counter to both. Interestingly, the narratives of participants were compatible with the self-evaluations of people exposed to other hardships (like natural disasters).

Originality/value - There is a limited research on how the use of counterfactual thinking and difference of vantage points shapes attitudes and evaluations of precariousness. To our knowledge, this is the first study which has identified and explained the unprompted use of 'luck' in the narratives of precarious workers.

Key words: Precariousness, Luck, Work Experiences, Job Insecurity, Short-term Work, Migrant

Workers, Counterfactuals

Article Type: Research paper 
Mikhail is Eastern European and disillusioned with life in his native country. He is struggling to make his rent payments and, after all bills are paid, there is little left for food. Having heard from friends that there is plenty of work in Britain which pays well, he decides to try his luck.

Once in Britain, Mikhail signs up with an agency which offers him short-term work. He is paid at the minimum-wage level, has to share a flat with several others to keep costs down, and is often called in to do shifts at a short notice. Mikhail is aware that there are better jobs out there and knows that many would not want to do what he does. Life in Britain is not easy, even so, Mikhail considers himself lucky. Although precarious, his present circumstances are an improvement on life at home.

The above narrative illustrates the gap between 'outside-in' perspectives and the workplace experience for a number of our interview respondents, and also indicates the intrusion of counterfactual thinking in critical life situations where worse, or better scenarios can be conceived (Epstude \& Roese, 2008; Roese \& Hur, 1997; Roese \& Olson, 1997). As shown in Mikhail's example, workers in low-pay, low-security, 'precarious' work may be tempted to compare the present context of work to an alternative scenario, rather than evaluating it objectively. Workers, like Mikhail, may not automatically be deterred nor regard themselves 'unlucky', if they can conceive of an alternative and much less desirable reality.

Using Girotto, Ferrante, Pighin, and Gonzalez's (2008) seminal categorisation, Mikhail may also be termed an 'actor', that is, a person actively taking part in experiencing a series of events. This perspective is likely to differ from that of a 'reader', that is, an 
external observer, who may produce a different set of interpretations and inferences. The role of 'actors' in our study is portrayed by those participants who are already placed in conditions of casual, low-pay and insecure work. The 'readers', on the other hand, are a panel of 56 business students who are invited to observe the condition from the 'outsidein', through a set of questions. A 'reader' could also be any labour market researcher, social psychologist, work sociologist, journalist or any other external observers, who interprets the condition of casual workers without access to the first-person information, which an 'actor' may possess.

The literature on low-pay, low-skill work prescribes a range of negative experiences for workers in those conditions. Vosko (2010) explicitly connects the limited benefits, entitlements and income of precarious jobs with a general state of uncertainty. For her, as for Standing (2014; 2011), Campbell and Price (2016), Arnold and Bongiovi (2013) and Kalleberg (2009) the defining feature of precarious work is multi-faceted insecurity, that is, insecurity due to the short duration of the employment relationship, limited regulation, and low-levels of pay. However, it is possible that social scientists, observing workers from the 'outside-in', and at a distance, are not drawing the same inferences as the workers themselves, given that the latter's perspective is from the 'inside-out', and at a closer range. Therefore, the aim of the present research is to compare and contrast the external, 'outside-in' perspective of social science observers, with the 'inside-out' view of workers in low-skill and low-pay employment.

\section{The 'outside-in' view of social science 'readers'}

The external, 'outside-in' view of 'readers' can be demonstrated through a brief outline of the research literature on low-skill, low-pay work. In this literature, two broad 
perspectives can be distinguished, one focusing on a unilateral 'liberalization' of labour markets, and others which highlight the growing 'dualization' and emergence of economic 'outsiders', a self-same 'precariat' (Emmenegger, 2009; Prosser, 2015; Standing, 2011).

The 'liberalization' perspective is represented as early as the 1980s, with Bourdieu (1998) commenting on the spread of 'précarité', translated as 'job insecurity', and its socially-disruptive effects. This view includes research on the rise of 'bad', 'lousy', 'dirty' and even 'tainted' jobs. Those can be found at the lower end of the employment market, and offer little in the way of meaningful remuneration, progression, security and worker rights (Grandy, 2008; Jacobs, 2014; Kreiner, Ashforth, \& Sluss, 2006; O’Connor, 2015; Sissons, 2011; Tyler, 2011). A comprehensive overview of the characteristics of precarious work can be found in Standing (2011), Vosko (2010) and the International Labour Organization's Labour Market Security Index (Campbell \& Price, 2016). Those include reduced worker access to a range of securities, such as regulatory protection through health and safety legislation, protection from arbitrary termination of the employment relationship, collective bargaining power, working times and working hours. Vosko (2010) explicitly connects the limited benefits, entitlements and income of precarious jobs with a general state of uncertainty. For her, as for Standing (2011, 2014), Campbell and Price (2016), Arnold and Bongiovi (2013), and Kalleberg, Reskin, and Hudson (2000) the defining feature of precarious work is multi-faceted insecurity, that is, insecurity over tenure (duration of the employment relationship), regulation, labour-process control, contractual protection and level of remuneration.

Although approaching the subject of precarious work from a different angle, the 'dualization' perspective also considers the negative effects of precarious conditions on those workers in them (Campbell \& Price, 2016). The 'dualization' discourse may be traced 
back to Atkinson and Meager's (1986) 'flexible firm' model, which considers the division of the workforce into a core of functionally-flexible employees, and a periphery made-up of numerically flexible workers, with the latter being prone to dismissal in line with the company's needs. Precarious workers can be placed into this category of numericallyflexible workers and can be accorded the status of 'economic outsiders' (Emmenegger, 2012, 2009), able to only access the 'bad' jobs which lack meaningful remuneration, progression opportunities or job control (Kalleberg, 2009). One particular aspect of precarious work, the incidence of zero-hour contractsi, has maintained a high media profile in Britain and seems to support the argument for the presence of, at best, an 'insecure workforce' (Heery \& Salmon, 2002), and at worst, a 'precariat' (Savage, Devine, Cunningham, Taylor, Li, Hjellbrekke, Le Roux, Friedman, \& Miles, 2013; Standing, 2011, 2014). As an example, zero-hour workers earn an average of $£ 188$ per week, compared to the $f 479$ for permanent workers (Farrell, 2016; Trades Union Congress, 2015). This has led commentators (see, for example Elliott, 2016; Trade Union Congress, 2016) to suggest that employer flexibility is achieved through the exploitation of workers, imposed to reduce workforce costs and side-step the full gamut of employment law obligations applicable in the instance of permanent employment. Although the negative impact of precarious work on corresponding experience can be moderated through task identity, improvements in job quality and so on, the rate of pay remains as a significant predictor for categorizing precarious work as 'bad jobs' (Kalleberg et al., 2000).

To sum up: From an external, professional point of view, and irrespective of the focus on precarious work as a structural (Arnold \& Bongiovi, 2013; Lewis, Dwyer, Hodkinson, \& Waite, 2015;) or existential condition (Butler, 2004); a personal (Hardgrove, Rootham, \& McDowell, 2015) or collective (Standing, 2011) experience, precarious work is generally 
viewed to have a negative impact on workers. Whether there is scope for mitigating the negative impact through social support, education and welfare (Arnold \& Bongiovi, 2013) or not; the insecure position of precarious workers is well-documented (Heery \& Salmon, 2002; Kalleberg, 2009; Standing, 2014, 2011; Vosko, 2010). Thus, an external 'reader' may conclude that precarious work less desirable than meaningful and secure forms of employment, but does it follow than this perspective is shared by insider 'actors', like Mikhail in our opening vignette? Let us ask Mikhail and listen to what he has to say.

\section{The 'inside-out' view of situational 'actors'}

Individuals also make sense of their situation and life conditions through a process of counterfactual comparison. But they do not simply compare themselves socially with groups that are better or worse off, as highlighted by social comparison theory (Buunk \& Gibbons, 2007; Festinger, 1954), they make comparisons with imaginable, alternative scenarios that 'might' or 'could' have been. Such counterfactual comparisons can are similar to social comparisons in being able to go both ways: Life could have been better, but it could also have been worse. This study, however, specifically focuses on the counterfactual comparisons of 'actors' and 'readers' and uses functional theories of counterfactual thinking (Epstude \& Roese, 2008) highlight why: Downward counterfactuals make us feel better, both with respect to mood and to self-esteem, whereas upward counterfactuals may provide the extra motivation needed to prepare for the future and improve our lot. Downward comparisons are accordingly particularly frequent in enduring situations where improvement is beyond the actor's control, whereas upward comparisons are more frequent in controllable situations that might be repeated in the future (Markman, Gavanski, Sherman, \& McMullen, 1993). Realities have also structural characteristics that make some aspects easier and others more difficult to change, even in our minds. Some 
aspects of reality are just taken for granted and will not allow for counterfactual speculations. For instance, we rarely spend much effort thinking that an accident could have been avoided by the temporary suspension of a law of nature (Seelau, Seelau, Wells, \& Windschitl, 1995). People find it is easier to mentally 'undo' a human act, particularly in areas where people have a history of acting otherwise (Byrne, 2016). As pointed out by Norm theory (Kahneman \& Miller, 1986), unusual happenings are more mentally mutable than those conforming to an expectation or a norm. Random events are also, by their very nature, easy to think could have turned out differently, as are all events where, perceptually or conceptually, another outcome appears 'close' (Kahneman \& Varey, 1990; Roese, 1997). Thus, a 'near miss' will, almost by definition, evoke downward counterfactual phantasies about a potential accident. It is important to note, that the vantage position of the person is significant here. As noted by Girotto et al. (2007), an 'actor' can draw on a complex set of antecedents: memories, experiences and external cues, in order to arrive at a counterfactual comparison. On the other hand, the external 'reader' can base a counterfactual judgement on a much simpler set of characteristics, and a more likely to compare a precarious context to a binary criteria: 'not as good as it could have been', or, 'better than it could have been'.

\section{Luck as a counterfactual experience}

Significantly, counterfactual comparison is a complex process. In this sense, even downward counterfactuals have an upside. They make people realize that reality is, in comparison, nicer, or more exactly: luckier than it might have been. Philosophical and psychological analyses of the concepts good and bad luck reveal that the experience of being lucky is essentially dependent on counterfactuals. Pritchard and Smith (2004) concluded that an outcome is lucky (1) if it occurs in the actual world, but not in other, 
nearby 'possible' (counterfactual) worlds, and (2) if it is significant to the agent concerned. The closer and worse the counterfactual alternative is perceived to be, the luckier you are (Teigen, 2005). This appears to contrast with the popular view that people are 'lucky' when something good happens to them, typically by chance (Rescher, 1995). But 'good' must here be taken in a relative sense. In students' narratives about lucky incidents from their own life, half of the events described were rated as more unpleasant than pleasant (Teigen, 1995). The events were lucky to the extent that they turned out better than the closest counterfactual alternative, as when a lost item was recovered, or a traffic accident resulted 'only' in material damage. Families returning from the 2004 Tsunami disaster in Southeast Asia surprised interviewers by telling how 'lucky' or 'fortunate' they had been. Such terms were used spontaneously in $90.6 \%$ of all narratives, whereas only one person mentioned an 'unfortunate' detail (Teigen \& Jensen, 2011). After the volcanic ash cloud incident in 2010 that paralyzed air traffic in North Western Europe for more than a week, passengers who were prevented from travelling declared themselves 'lucky' not to be stranded abroad. Perhaps ironically, those who were unable to return as planned rated themselves as even luckier, as they could easily have imagined their situation to have been still worse (Teigen \& Glad, 2011). In both cases the disasters appear to be taken for granted, the closest counterfactuals being imagined worst-case scenarios. For outsiders that have not been personally exposed, the situation looks different. To them, Scandinavian tourists who had decided to spend their Christmas holidays in Thailand were unlucky both in respect to timing and destination, and those who were travelling by air in April 2010 were exposed to a most unfortunate series of cancellations and delays. These examples suggest that perspective and distance to the event may affect people's choice of counterfactuals by making different aspects of the situation salient and mentally mutable. 


\section{Construal level}

Events can be perceived as distant or as close, not only in a geographical, but also in a temporal, hypothetical, or social sense. According to construal level theory (Liberman \& Trope, 2008; Trope \& Liberman, 2010), such distances are psychologically similar, in that they make an observer think about events that are near at hand in more concrete terms; whereas more distant events, for instance those taking place in the far future or in a remote location are typically perceived in a more schematic, abstract way. Construal level theory (CLT) has shown itself as a useful framework for explaining why people emphasize different aspects of a situation at a distance versus close at hand. For instance, distant tasks are judged based desirability (general principles for why they should be performed), whereas close tasks are typically chosen based on feasibility considerations (how should they be managed) (Liberman \& Trope, 1998; 2008). At a distance, one sees mainly the forest, approaching, one will begin discriminating trees. In parallel, one might think that the counterfactuals of close and distant events may also differ. This idea could also be applied to different construals and evaluations of precarious work conditions. At a high level of construal, one may compare different classes of workers to each other, and think that uncertain and temporary jobs "should" be secure; at a lower level, with focus on the here and now, a worker may compare current jobs with concrete episodes of unemployment, as experienced by himself or by acquaintances. From this it makes sense that researchers, looking at the labour market from the outside and 'above' will discuss precarious work primarily in terms of upward comparisons, as demonstrated by our initial literature review. From the perspective of the individual workers such structural aspects of society may not be to the same degree open for debate. Like natural disasters, social inequalities may be taken for granted as the (deplorable) way that 'things are', and the focus of attention is primarily 
directed towards situational features that have been experienced, or can be imagined as better or worse. From this perspective, individuals will be able to discern 'lucky' aspects even in a troublesome life.

\section{The present research}

A starting point for the present research was our recognition of the need to consider and study potentially divergent interpretations of precarious experiences, namely, 'actors' experiencing precarity from the 'inside-out' and 'readers' observing it from the 'outside-in'. The panel of 'readers' were presented with four, Likert-scale questions. It was anticipated that scores below the middle of the scale would indicate an upward construal ('present conditions could be better'), while higher scores suggested downward ('not as bad as could have been') comparison. In addition, and in order to study 'actor' experiences in detailed richness, in-depth interviews grounded in a phenomenological paradigm of enquiry were used (Moustakas, 1994; Sokolowski, 2000). Such narratives were expected to contain evaluations based on counterfactual comparisons by how work life and work conditions could have been better, or worse. Two competing hypotheses could be formulated:

(a) From an 'inside-out' perspective, precarious 'actors' may make downward counterfactual comparisons, if such scenarios are to them more imaginable and available than upward ones, leading to descriptions of themselves as more lucky than unlucky. Downward comparisons may also be preferred for motivational reasons, protecting their self-esteem and offering consolation (Byrne, 2002), a factor not likely to influence the panel of 'readers'.

(b) The difficulties and disadvantages inherent in precarious work might induce 'readers' to make upward comparisons with workers who are permanently 
employed, in line with the 'outside-in' view delineated above. This comparison would make external observers describe those in precarious works as more unlucky than lucky.

\section{Study 1: The 'Actors'}

\section{Method}

Study 1 took place in the South West of Britain over the 2014-2016 period (see Appendix A for Study 1 interview questions). The lead researcher carried-out individual and focus-group interviews with a total of 72 participants across three precarious groups, including migrant workers $(n=9)$, cleaners and hospitality $(n=28)$, and nursery and social care workers ( $n=35$ ). Of these, 16 (approx. $22 \%$ ) had transitioned into low-skill and lowpay work from a previous job, whereas 56 (approx. 78\%) had taken up work after a previous period of unemployment. In the 48 individual, in-depth interviews, three main themes were explored: 1) worker views about their current working environment; 2) worker views about the employer; 3 ) worker views about their colleagues. This format was adopted to encourage participants to reflect on different aspects of their working environments (Kvale, 1996). The approached allowed the application of counterfactual thinking without explicitly soliciting the use of counterfactuals. In addition, the three themes above were investigated through four focus groups with a total of 28 participants. The focus groups were made-up of zero-hour cleaner and hospitality workers, paid on an hourly rate based on the minimum wage and working across different departments in a large international corporation based in the South West of Britain. Table 1 presents an overview of participant demographics.

Table 1 about here 
The interview protocols were transcribed professionally through an 'intelligent verbatim' style, and analysed by two independent coders (Girotto et al., 2007), using content coding of 'natural meaning units' (Kvale, 1996), and then thematically analysing them (Bryman \& Bell, 2015). Only counterfactual thoughts with an alternative were coded ("I am lucky to be working, as there isn't much work available"). Agreement between the first and second coder was over 95\%, and all disagreements were resolved following a discussion.

\section{Results}

Respondents in focus groups and individual interviews described a wide variety of personal experiences, including a range of achievements, problems and challenges. Almost half of these $(n=22)$ spontaneously used terms denoting 'good' or 'bad' luck (through such derivations as lucky, unlucky, fortunately), with 20 statements bringing up the notion of luck in a positive way against only two participants bemoaning their bad luck $(p<.001$ with binomial test). Thus, hypothesis (a) was supported.

Downward counterfactuals were not limited to respondents who had been previously unemployed. Indeed, it seemed easier for precarious workers to compare their situation downwards with circumstances that could have been worse, when they had previous experience of precarious work. Perhaps surprisingly, most of those who said they were lucky came from the group who had been working in the past; $\chi^{2}(1,72)=25.99, p<$ .001. Luck statements revolved around three main themes: Participants who felt they were lucky to be working, lucky to have family and friends, and lucky to have collegial support, as illustrated in separate sections below.

Lucky To Be Working. A prominent aspect of the 'luck' experience was participants' perceptions of being lucky to get a job. In the narration of this aspect of luck, the precarious 
nature of the job did not seem to preclude the worker from appreciating access to gainful employment, nor to be grateful for a job being available. Workers did not seem to make a distinction between different types of employment, nor seem to consider a hierarchy of employment, for instance, with casual work being at the bottom and secure work at the top. The dichotomy of 'good jobs vs. bad jobs' (see, for example, Kalleberg, 2009) did not seem to exist for workers, for whom being in work - any work - was a much better alternative than lacking employment.

This was the case with male Bulgarian migrant 'Evgeny', who had had a difficult time upon first arriving in Britain. Not only were his expectations of immediate employment not met, but the reality which first of all he, and later his family encountered transformed his expectations. Consequently, Evgeny was forced to adjust those expectations, in order to match the reality of life as an immigrant in Britain. Surprisingly, it was against this backdrop of negativity that he managed to find work and, consequently, counted himself 'lucky':

"I was lucky, though, because the B\&B owner let me work for him doing some painting, and there was also a big construction site right in front of the $B \& B$ where I started working as well, so I was able to apply for a national insurance number."

(Evgeny, Male, Self-Employed Painter and Decorator)

Evgeny explained that had these events not taken place, he would have had to continue dipping into his savings, which was a much worse option than having short-term work. The experience of Bulgarian care worker 'Gergana' was constructed along similar premises. She had come to the UK on account of what she described as 'necessity', trying to find a way to re-pay the debts she had accrued in Bulgaria. She had arrived in the UK 
without any particular expectations to earn a significantly higher amount of money. She was aware of her low-level English and felt that she was looked down on, for being a migrant and yet, she was able to not only find work, but work within a close commute from home, too. This was not the experience she had hoped for, but a better option than having to go back home.

"[When] I came to the UK, I was hoping to earn enough money to pay my debts [in her native country]. Unfortunately it didn't happen this way...I was lucky though, because I was able to find work (...)"

(Gergana, Female, Care Worker)

The binary juxtaposition of employment against non-employment was also prominent in the experiences of workers in the four focus groups, who expressed their perception that work availability was diminished, and especially so in the South West of Britain where the role of mining and fisheries, as the main sources of employment, had declined and replaced by a service-economy (Manolchev, 2016). In line with this, the sheer offer of employment was enough to bring-about downward counterfactual thinking with workers considering themselves 'lucky' simply for having a job, or being able to keep it:

"There aren't that many jobs, so you are lucky to be offered one."

(Participant P, Focus Group 3)

"I am lucky that I can do my job, and lucky to be in a good environment."

(Participant U, Focus Group 3) 
We anticipated that the application of downward counterfactual thinking with regards to finding work would give way to a dissatisfaction with the terms and conditions, as workers spent more time in their current role. This, however, was not the case. Even when their employer required them to change roles, participants instead felt they were 'lucky' to have had the experience:

“I'm quite lucky, as I've worked at the bottom, I've been in the middle and I've even been at the top. I know how it works, because I worked my way up. I knew what needed changing, I knew what the employer needed, and I have used my expertise as I progressed."

(Renee, Female, Hotel Caterer)

Lucky to Have Support. The second theme of luck appearing in participant narratives referred to the availability of support, for instance, that of friends and family. The work experience is embedded in a social context with actors and supporters that do not belong to the workplace, but are still essential for making work-life meaningful and feasible. Furthermore, and unlike the contractual provisions of employment, which appeared to be outside individuals' control, workers could and did choose to call upon their family members, and friends. Realizing that their debts to these external helpers were vital, but could not be taken for granted, several respondents declared themselves 'lucky' to have support, rather than having to cope alone.

"I'm lucky because they [her children] have grandparents that help out, when I'm working I know they are spending time with grandparents as well." 
Downward counterfactual thinking and 'luck' narratives could be applied to instances when a worker had colleagues on whom to rely, and in whom to confide. In this way participants saw themselves as 'lucky' on account of having access to a good team and choosing to connect with their colleagues, regardless of the specific context of work, or their own personal position within the hierarchy of the given structure of employment. The significance of colleagues also seemed greater than the any particular aspects of the job, terms and conditions or duration of the contract.

"I do say to a lot of girls, I'm in a very, very lucky position compared to some because you know my husband supports me on whatever I want to do."

(Joanne, Female, Nursery Nurse)

This awareness and reliance on colleagues was also present in the narratives of focus-group participants, who considered themselves 'lucky' on account of having their peers' support. Downward counterfactual representations of precarious work occurred with regards to evaluating perceptions of participants' own team, also. This, in turn, enabled precarious workers to actively transform fellow-employees into the category of 'friends'.

In the below narratives, participants exhibit downward counterfactual thinking by suggesting that the kind of people they encounter at work, make them more fortunate than others. Specifically, having collegial support in the present, a situation often deemed surprising and unexpected by our participants drove the downward counterfactual. 
"I am very lucky to be working in a squadron where everyone, no matter what their rank is, are very nice, as long as you do a good job and be yourself everyone is really polite, you wouldn't get that in a civilian environment."

(Participant O, Focus Group 3)

"We are quite lucky in the wardroom as we do work as a team, one lady is off-sick at the moment and between ourselves we have all jumped in to do her work."

(Participant C, Focus Group 1)

\section{Study 2: The 'Readers'}

From the way precarious work is discussed in the literature, we might have expected that the poor quality of work, insufficient rates of pay and lack of control over work allocation would induce precarious 'actors' to come-up with upward counterfactual comparisons of the 'my job could have been much better' type. Yet, the precarious workers in our sample failed to narrate the negative experiences, which the literature associated with the terms and conditions of low-skill, low-pay and low-tenure work.

Perhaps this is not surprising, given that the research literature is taking a perspective more akin to the role of external observer, or a 'reader'. Such a high construal, bird's eye perspective on different work conditions requires that full-time and permanent jobs are taken as the norm, from which other work contracts deviate from. From this perspective, the disadvantages of precarious work loom larger than its advantages. However, this literature does not claim to predict individuals' own evaluations and descriptions of their work situation. Studies of counterfactual thinking have shown that individuals can describe themselves as lucky under difficult circumstances and precisely in 
challenging situations (Teigen, 1995; Teigen \& Jensen, 2011). This may or may not be anticipated by 'outsiders' who are asked to give their views on what they think precarious workers feel about their work. To address this question, we performed a second study, with a group of undergraduate students from a business background. These participants were automatically assigned to the role of 'readers', looking at the matter of precarious work from the 'outside-in', indicating their own opinions and not required to simulate the views and experiences of precarious workers.

\section{Method}

Participants in Study 2 were 56 (36 females and 20 males) business undergraduates at the University of Exeter, UK, who volunteered to take part. They were presented with two vignettes of precarious work based on Study 1, and then invited to answer a four-part questionnaire.

The first vignette presented a broadly negative experience, which combined several similar narratives in Study 1 . The second vignette outlined a broadly positive experience, also drawn from Study 1 . The panel was then able to address the researcher with questions regarding the two precarious conditions portrayed in the vignettes. The participants were then asked to complete a four-item questionnaire designed to test their perception of what precarious work is like in terms of feeling 'fulfilled', 'happy', 'satisfied' and 'lucky' (see Appendix A for the questionnaire).

Participants indicated their responses as ratings on a separate, four-point questionnaire, in accordance with how they imagined a typical precarious worker would describe his or her work situation, from 1 to 5 . Scores below the scale midpoint at 3 indicate that participants saw precarious workers to be more unhappy than happy, more unlucky than lucky, and so on. 


\section{Results}

Mean ratings indicate that precarious workers are judged close to the neutral point of these scales, although slightly likely to be unhappy $(M=2.79)$, unfulfilled $(M=2.59)$, and unsatisfied $(M=2.79)$. Crucially, the 'luck' evaluations indicated that precarious workers are deemed to be slightly more unlucky than lucky $(M=2.77)$, in moderate support of hypothesis (b) and suggesting that the notion of good luck is not one which is ordinarily associated with the precarious work experience, by external respondents.

\section{Discussion}

The studies reported in the present article enrich and supplement our understanding of what precarious work can be like. The experiences of respondent 'actors' deviate both from scholarly descriptions of a disadvantaged 'precariat' and from the expectations of a panel of "lay" people ('readers'). As already suggested, it has previously been found that 'actors' and 'readers' who are presented with the same situation do not necessarily bring up the same counterfactuals (Girotto, Ferrante, Pighin, \& Gonzalez, 2008). 'Actors' can be more concerned with factors close to the outcome, and 'readers' might take a more distant view and can more easily imagine a variation in the causal conditions. Crucially, the acknowledgement of such a distinction in perspectives is markedly absent in the precarious work literature.

Consequently, we suggest that something similar may be going on when workers are telling their stories, compared to the views of 'outsiders' (scholars, external observers and our sample of lay people). More specifically, workers did not use upward counterfactual thinking to assess their position against the objective terms and conditions of their employment, nor found their employment circumstances inferior, for instance, to an alternative, more secure or better paid option they would have preferred. Rather, the use of 
positive luck statements indicated downward counterfactual thinking, with workers considering how their circumstances and their achievements could easily have been worse. This was especially so for workers who have been out of work before and, perhaps, recalled the negative experiences associated with job loss, and the pressures of job search. Therefore, although precarious work could be deemed undesirable and insecure, workers in our sample evaluated it against the conceivable possibility, or recent experience, of even worse circumstances. Consequently, participants found it easier to imagine themselves working for less pay or losing their job altogether, than to envisage being in a wellremunerated and stable job. Thus, the use of 'luck' in our sample occurred because the deterioration of current working contexts was in closer construal proximity for precarious workers, than the high-construal and abstract notion of 'better work' (Henderson, Fujita, Trope, \& Liberman, 2006; Trope \& Liberman, 2010).

This insight goes against the suggestion that workers view their employment as part of an objectively-identified hierarchy, with temporary work at the bottom and secure employment at the top. The attitudes in 'actors' in our sample work presented a much simpler outlook, where work and work support was to be valued and appreciated regardless of duration, or level of pay. Such an attitude is understandable and perhaps contributes to workers attaining a positive self-image management and a strategy to avoid disappointment and regret. Conversely, our panel of undergraduate 'readers' were more likely to assess precarious work in objective terms, that is, as an unsatisfactory condition which workers ought to seek improvement upon, and come-up with a different set of counterfactual judgements

Although carried-out within the geographical limitations of the South West of Britain, the implications of our study are significant. It is able to consolidate two competing 
perspectives of precarious work and explain how positive and negative assessments can coexist, depending on the 'role' of the observer (Girotto et al., 2007). Furthermore, we are able to show that it would be premature to assume that precarious work has a consistently, and a consistently-negative impact on workers, nor is it possible to assume that precarious workers would collectivise, simply because they share similar contexts. Although counterfactual thinking and CLT do not deny the possibility for negative experiences at work, the process through which contexts are constructed and evaluated appears to be complex. However, we would like to emphasise that our findings should not be taken as a call to lower the quality of working conditions for all in the hope that some would have experienced much worse in the past. Rather, our study calls for further and more detailed research in other precarious groups and their experiences, as well as a careful consideration of the position of researchers evaluating precarious work.

The studies also add to our knowledge about the circumstances under which people are willing to describe themselves as lucky. Spontaneous use of such terms has, to our knowledge, only been recorded in a disaster study (Teigen \& Jensen, 2011), where the counterfactual alternative (being killed by the tsunami) was dramatically present. Their use by precarious workers is less obvious, as one might think that upward counterfactuals were for them equally available, particularly for those who had held previous jobs. Perhaps paradoxically, this group was even more inclined to describe themselves as "lucky" than those who had a history of previous unemployment.

Two explanations are possible. One is of a motivational nature, and we propose that those who have lost a previous job would be more likely to compare themselves downwards to preserve their self-esteem and to feel better about their current situation. The other follows from a dynamic rather than static view of counterfactual closeness and, in line with 
Kahneman \& Varey (1990) and Maglio \& Polman (2014) we pose that people feel closer to a destination towards which they appear to be heading than to a destination they have left behind. For someone who has lost a previous job, unemployment is not far away, and it becomes urgent to stress that one has been "lucky" to avoid this threat.

For outsiders the use of upward counterfactuals appeared to offer a better fit, especially when comparing precarious working contexts with secure, well-remunerated and safer employer at the opposite end of the spectrum. Our purpose with this research is not to disprove the validity of this comparison, or play down the difficulties experienced by precarious workers, but to add a facet that might easily be overlooked by a high-construal, 'outside-in' perspective. It could be suggested that the 'inside-out' perspective offered a unique vantage point, that of close construal proximity terms. This proximity highlighted the insecure predicament of workers in our sample, who could do little to avoid, opt-out or move-away from their precarious jobs. At the same time, it also meant that workers were less likely to evaluate their contexts objectively, or undertake evidence-based comparisons between their current role, and another with better rates of pay, security and so on. The proximity between worker and work, as defined in construal level theory terms, provided workers with a unique strategy for re-constructing their precarious contexts. Workers did so by first, accepting the inevitability of their precarious contexts and second, by being grateful for the opportunity be in work and benefit from the support of colleagues, friends and family. Rather than engaging with their precarious environment on an abstract, higherconstrual level and bemoaning their current condition for presenting a less-than-desirable outcome, workers viewed the present reality as the only possible one. This, in turn, did away with the 'temptation' to apply upward counterfactuals, and consider all the ways in which their jobs could have been better. Instead, workers were grateful for being able to 
utilise a combination of work, friends, family and colleagues, in order to achieve outcomes, which were viewed as more positive than what could have been. Thus, our interviews suggest that workers used the term 'lucky' (and its derivatives), to denote favourable outcomes occurring against the odds of precarious working contexts, which appeared to be placed outside individual control. We are used to think of personal control as a key factor for work and life satisfaction (Cheung, Kroese, \& de Ridder, 2014; Salmansohn, 2011), but even so, being favoured by chance is not to be despised. 
Table 1. Participant Demographics, Study 1.

\begin{tabular}{|c|c|c|c|c|}
\hline Group & $\mathbf{N}$ & Gender & $\begin{array}{l}\text { Interview } \\
\text { County }\end{array}$ & Method \\
\hline Migrants & 9 & $4 \times F ; 5 \times M$ & $\begin{array}{l}\text { Cornwall, } \\
\text { Devon }\end{array}$ & $\begin{array}{l}\text { In-depth individual } \\
\text { interviews }\end{array}$ \\
\hline $\begin{array}{l}\text { Nursery and } \\
\text { Social Care }\end{array}$ & 35 & $33 \times F ; 2 \times M$ & Cornwall & $\begin{array}{l}\text { In-depth individual } \\
\text { interviews }\end{array}$ \\
\hline $\begin{array}{l}\text { Cleaners and } \\
\text { Hospitality }\end{array}$ & 28 & $20 \times F ; 8 \times M$ & Cornwall & $4 \times$ Focus groups \\
\hline Total & 72 & & & \\
\hline
\end{tabular}




\section{References}

Arnold, D., \& Bongiovi, J. R. (2013). Precarious, informalizing, and flexible work:

Transforming concepts and understandings. American Behavioral Scientist, 57(3), 289-308.

Atkinson, J., \& Meager, N. (1986). New forms of work organisation. Brighton, UK: Institute of Manpower Studies.

Bourdieu, P. (1998). Acts of resistance: Against the tyranny of the market. New York: New Press.

Bryman, A., \& Bell, E., 2015. Business research methods. Oxford: Oxford University Press.

Butler, J. (2003). Precarious life: the powers of mourning and violence. New York: Verso Books.

Buunk, A. P., \& Gibbons, F. X. (2007). Social comparison: The end of a theory and the emergence of a field. Journal of Organizational Behavior and Human Decision Processes, 102, 3-21.

Byrne, R. M. J. (2002). Mental models and counterfactual thinking. Trends in Cognitive Sciences, 6, 405-445.

Byrne, R. M. J. (2016). Counterfactual thought. Annual Review of Psychology, 67, 135-157.

Campbell, I., \& Price, R. (2016). Precarious work and precarious workers: Towards an improved conceptualisation. The Economic and Labour Relations Review, 27(3), 314332.

Cheung, T., Kroese, F. \& de Ridder, D., 2014. Why more self-control makes you happier. examining the relationship between self-control, regulatory focus, and happiness. European Health Psychologist, 16(S), 423.

Elliott, L. (2016). A zero-hours contract is not 'flexibility' but exploitation - and it's rising. [online] The Guardian. Available at: 
https://www.theguardian.com/business/2016/mar/09/zero-hour-contract-is-notflexiblity-but-exploitation-and-its-rising [Accessed 9 Mar. 2017].

Emmenegger, P. (2009). Barriers to entry: Insider/outsider politics and the political determinants of job security regulations. Journal of European Social Policy, 19(2), 131-146.

Emmenegger, P. (2012). The age of dualization: the changing face of inequality in deindustrializing societies. Oxford: Oxford University Press.

Epstude, K., \& Roese, N. J. (2008). The functional theory of counterfactual thinking. Personality and Social Psychology Review, 12, 168-192.

Farrell, S. (2016). UK workers on zero-hours contracts rise above 800,000. [online] Available at: https://www.theguardian.com/uk-news/2016/mar/09/uk-workers-on-zerohours-contracts-rises-above-800000 [Accessed 9 Mar. 2017].

Festinger, L. (1954). A theory of social comparison processes. Human Relations, 1, 117-140.

Girotto, V., Ferrante, D., Pighin, S., \& Gonzalez, M. (2007). Postdecisional counterfactual thinking by actors and readers. Psychological Science, 18, 510-515.

Grandy, G. (2008). Managing spoiled identities: dirty workers' struggles for a favourable sense of self. Qualitative Research in Organizations and Management: An International Journal, 3 (3), 176-198.

Hardgrove, A., Rootham, E., \& McDowell, L. (2015). Possible selves in a precarious labour market: Youth, imagined futures, and transitions to work in the UK. Geoforum, 60, 163-171.

Heery, E., \& Salmon, J. (2002) The insecure workforce. London: Routledge. 
Henderson, M.D., Fujita, K., Trope, Y., \& Liberman, N. (2006). Transcending the" here": the effect of spatial distance on social judgment. Journal of Personality and Social Psychology, 91(5), 845-856.

Jacobs, K. (2015). Job quality in an hourglass labour market. HR Magazine, 16 February [Online]. Available at: http://www.hrmagazine.co.uk/article-details/jobquality-in-anhourglass-labour-market (Accessed: 14/03/2016).

Kahneman, D., \& Miller, D. T. (1986). Norm theory: Comparing reality to its alternatives. Psychological Review, 93, 136-153.

Kahneman, D. \& Varey, C. A. (1990). Propensities and counterfactuals: The loser that almost won. Journal of Personality and Social Psychology, 59, 1101-1110.

Kalleberg, A. L. (2009). Precarious work, insecure workers: Employment relations in transition. American Sociological Review, 74 (1), 1-22.

Kalleberg, A. L., Reskin, B. F., \& Hudson, K. (2000). Bad jobs in America: Standard and nonstandard employment relations and job quality in the United States. American Sociological Review, 65, 256-278.

Kreiner, G. E., Ashforth, B. E., \& Sluss, D. M. (2006). Identity dynamics in occupational dirty work: integrating socialization. Organization Science, 17(5), 619-636.

Kvale, S. (1996). Interviews: an introduction to qualitative research interviewing. London: SAGE.

Lewis, H., Dwyer, P., Hodkinson, S., \& Waite, L. (2015). Hyper-precarious lives: Migrants, work and forced labour in the Global North. Progress in Human Geography, 39(5), $580-600$. 
Liberman, N., \& Trope, Y (1998). The role of feasibility and desirability considerations in near and distant future decisions: A test of temporal construal theory. Journal of Personality and Social Psychology, 75, 5-18.

Liberman, N., \& Trope, Y. (2008). The psychology of transcending the here and now. Science, 322, 1201-1205.

Maglio, S. J., \& Polman, J. (2014). Spatial orientation shrinks and expands psychological distance. Psychological Science, 21, 345-1352.

Manolchev, C. (2016). Precarity and precariousness-a study into the impact of low-pay, lowskill employment structures on the experiences of workers in the South West of Britain (Doctoral dissertation, University of Plymouth).

Markman, K. D., Gavanski, I., Sherman, S. J., \& McMullen, M. N. (1993). The mental simulation of better and worse possible worlds. Journal of Experimental Social Psychology. 29, 87-109.

Moustakas, C. E. (1994). Phenomenological research methods. London: SAGE.

O'Connor, S. (2016). When your boss is an algorithm. Financial Times. [online] Available at: https://www.ft.com/content/88fdc58e-754f-11e6-b60a-de4532d5ea35 [Accessed 22 Feb. 2017

Pritchard, D., \& Smith, M. (2004). The psychology and philosophy of luck. New Ideas in Psychology, $22,1-28$.

Prosser, T. (2015). Dualization or liberalization? Investigating precarious work in eight European countries. Work, Employment \& Society, 6, 949-965.

Rescher, N. (1995). Luck: The brilliant randomness of everyday life. New York: Farrar, Straus \& Giroux.

Roese, N. J. (1997). Counterfactual thinking. Psychological Bulletin, 121, 133-148.

Roese, N. J., \& Hur, T. (1997). Affective determinants of counterfactual thinking. Social Cognition, 15(4), 274-290. 
Roese, N. J., \& Olson, J. M. (1997). Counterfactual thinking: The intersection of affect and function. Advances in Experimental Social Psychology, 29, 1-59.

Salmansohn, K. (2011). The No. 1 contributor to happiness. [online] Psychology Today. Available at: https://www.psychologytoday.com/blog/bouncing-back/201106/the-no-1-contributorhappiness [Accessed 9 Mar. 2017].

Savage, M., Devine, F., Cunningham, N., Taylor, M., Li, Y., Hjellbrekke, J., Le Roux, B., Friedman, S., \& Miles, A. (2013). A new model of social class? Findings from the BBC's Great British Class Survey Experiment. Sociology, 47(2), 219-250.

Sissons, P. (2011). The hourglass and the escalator [Online] Available at: http://www.theworkfoundation.com/downloadpublication/report/292_hourglass_escal ator120711\%20(2)\%20(3).pdf (Accessed: 14/03/2016).

Sokolowski, R. (2000). Introduction to phenomenology. Cambridge: Cambridge University Press.

Standing, G. (2011). The precariat: The new dangerous class. London: Bloomsbury Academic.

Standing, G. (2014). A precariat charter: From denizens to citizens. London: Bloomsbury Academic.

Teigen, K. H. (2005). When a small difference makes a big difference: Counterfactual thinking and luck. In D. R. Mandel, D. J. Hilton, \& P. Catellani (Eds.), The psychology of counterfactual thinking (pp. 129-146). London: Routledge.

Teigen, K. H. (1995). How good is good luck? The role of counterfactual thinking in the perception of lucky and unlucky events. European Journal of Social Psychology, 25, 281-302.

Teigen, K. H. (1997). Luck, envy, and gratitude: It could have been different. Scandinavian Journal of Psychology, 38, 313-323.

Teigen, K. H., \& Glad, K. A. (2011). "It could have been much worse": From travellers' accounts of two natural disasters. Scandinavian Journal of Hospitality and Tourism, $11,237-249$. 
Teigen, K. H., \& Jensen, T. K. (2011). Unlucky victims or lucky survivors: Spontaneous counterfactual thinking by families exposed to the tsunami disaster. European Psychologist, 16, 48-57.

Trades Union Congress (2015). New report on zero-hours contracts is not representative, says TUC. [online] Available at: https://www.tuc.org.uk/workplace-issues/new-report-zero-hourscontracts-not-representative-says-tuc [Accessed 9 Mar. 2017].

Trades Union Congress (2016). Living on the Edge: The rise of job insecurity in modern Britain. Economic Report Series. [online] Trades Union Congress. Available at: https://www.tuc.org.uk/sites/default/files/Living\%20on\%20the\%20Edge\%202016.pdf [Accessed 9 Mar. 2017].

Trope, Y., \& Liberman, N. (2010). Construal-level theory of psychological distance. Psychological Review, 117(2), 440-463.

Tyler, M. (2011). Tainted love: From dirty work to abject labour in Soho's sex shops. Human Relations, 64(11), 1477-1500.

Vosko, L. F. (2010). Managing the margins: Gender, citizenship, and the international regulation of precarious employment. Oxford: Oxford University Press. 
Appendix A

Migrants only:

- Why did you decide to move to the UK?

- Probe: Were there any issues at home? Any particular expectations you had?

- How do you feel about life in the UK?

All:

- Could you tell me a little about what you do?

- Why did you take up this job?

- How do you feel about your current working environment?

- Probe: has anything changed? What impact if any does it have on your life?

What did you expect of the job?

- How do you feel about your employer?

- Prompt: have your views changed since starting? How would you describe your relationship with the employer?

- How do you view/perceive your colleagues?

Prompt: Have your views changed since joining? How would you describe your relationship with your colleagues?

- Thank you and in conclusion - any else you wish to discuss? 


\section{Appendix B}

\section{Precarious Work Vignette \# 1:}

Andy works in a meat-processing factory. His contract is for 35 hours a week and pays him an hourly wage slightly above the minimum. This is not Andy's dream job, but he has, so far, been unable to find better work. Andy and his girlfriend, Rachel, are trying to save for a house deposit, but Rachel was recently made redundant from her position as a secretary and now does shift-work at a hotel in a neighbouring town. Unable to keep-up rent payments or get any benefits, they've had to move in with her parents, until Rachel finds a better-paid job. The whole experience has made Andy angry with the state support system which, for him, 'has got it all wrong'.

\section{Precarious Work Vignette \# 2:}

Maryia is an Eastern European nurse in her later 50s. She moved to the UK 5 years ago and now works as care assistant in an old people's home. Maryia is substantially over-qualified for the low-skill type of work she does and currently earns less than she did in her native country. This is not a problem for her though, as she gets on with colleagues and residents. She is not looking to change, or trying to find a better-paid job. When asked by residents if she enjoys being 'over here', Maryia answers that life in the UK is 'good, because she doesn't have to worry about anything'. She lives within her means and is happy to take on all the extra hours offered to her.

\section{Questionnaire}

A: How satisfied do you think a person in precarious work is?

$1=$ very dissatisfied; 2 = dissatisfied; 3 = neither dissatisfied, nor satisfied; 4 = satisfied; 5 = very satisfied

B: How happy do you think a precarious workers is?

$1=$ very unhappy; $2=$ unhappy; $3=$ neither unhappy, nor happy; $4=$ happy $5=$ very happy

C: How fulfilling do you think precarious work can be?

1 = very unfulfilling; 2 = unfulfilling; 3 = neither unfulfilling, nor fulfilling; 4 = fulfilling; $5=$ very fulfilling

D: How likely do you think precarious workers may consider themselves?

$1=$ very unlucky; 2 = unlucky; 3 = neither unlucky, nor lucky; 4 = lucky; 5 = very lucky 
'A zero-hour contract is a contractual arrangement in UK employment law, where the employer is under no obligation to guarantee working hours to the employee. This lack of obligation is reciprocated and, when offered, the employee is not obliged to accept. For more information, see Trade Union Congress, 2016. 